\title{
Laughing and Crying About Anesthesia: A Memoir of Risk and Safety
}

\author{
Gerald Zeitlin. Allandale Publishers, Chestnut Hill, MA and London England, 2011, \\ 263 pages, ISBN 1463798067
}

\author{
Kim E. Turner, MD
}

Received: 30 November 2012 / Accepted: 6 December 2012/Published online: 19 January 2013

(C) Canadian Anesthesiologists' Society 2013

A memoir can be defined as an account of something noteworthy or a narrative composed from personal experience. Dr. Zeitlin easily fulfills these definitions in his memoir. He is a storyteller who describes his personal accounts as "like a braided cord. Each thread has to be considered and then carefully wound into the core." Dr. Zeitlin writes in a charming and frequently humorous manner that is often self-deprecating, sometimes poignant, and occasionally caustic. He never loses site of his central theme, namely, the progression toward the reduction of risk and enhancement of patient safety he has witnessed during his career as an anesthesiologist.

Dr. Zeitlin's personal narrative begins with his life as an intern and his introduction to anesthesia while caring for patients with polio during the time when the first respiratory intensive care units were being developed. Having made anesthesia his career choice, he humorously relates the start of his initial interview with the esteemed Sir Robert Macintosh by describing how Sir Robert emerged naked, dripping wet from a shower, and searching for his towel. Dr. Zeitlin recounts his brusque introduction to independent administration of anesthesia, including his inability to sleep the night before. He humbly recalls the following day when he administered his first anesthetic for a gynecological procedure. During the procedure, the patient freed her legs from the stirrups and curled them around the operating surgeon causing him to cry out, "She's asphyxiating me!" This outburst was quickly

Dr. Zeitlin is generously donating a portion of his book royalties to the Foundation for Anesthesia Education and Research (FAER).

K. E. Turner, MD ( $\square)$

Queen's University, Kingston, ON, Canada

e-mail: turnerk@kgh.kari.net followed by an inquiry as to the whereabouts of Dr. Zeitlin's supervisor. Dr. Zeitlin writes of events and individuals he encountered throughout his training in England as well as during his career in private and academic institutions within England and the United States until his retirement. He skillfully weaves many of the important developments and events in anesthesia into his many personal vignettes and reminiscences; these include the actual discovery of anesthesia, the Chloroform Commissions, and the formulation of guidelines and standards, to name but a few. All are described with the backdrop of reduced risk and improved patient safety. Dr. Zeitlin includes portrayals of many of the personalities he encountered on both sides of the ether screen, those individuals who populated his life within the context of evolving tolerance for, shall we say, eccentric or perhaps even abusive behaviour during his training and professional practice on both sides of the Atlantic. Dr. Zeitlin's touching recollection, now 42 years later, of the death of a 19-yr-old woman who suffered cardiac arrest during an elective procedure illustrates not only our perioperative concern for protecting our patients from harm but also the personal emotional repercussions we experience following the death of a patient. This particular chapter entitled "What went wrong?" evolves into a discussion of Dr. Zeitlin's involvement many years later in the American Society of Anesthesiologists Closed Claims Project. He concludes this chapter with his caustic description of the haggling of the lawyers and culminates with his simple statement, "I still feel guilty because a young woman died". The patient had ultimately died of sepsis.

In the preface, Dr. Zeitlin states that he wrote this book for "the interested non-medical reader". In my view, this book would appeal to any individual who is interested in the history of our profession and is looking to gain insight 
into the daily challenges we face as anesthesiologists. While this is not a history text, Dr. Zeitlin has incorporated an astonishing volume of historical events into his memoir. It is an enjoyable read, though rambling at times; each chapter can be read on its own. If I have but one criticism of the book, it is the difficulty in determining the actual subject matter or the location of a favourite anecdote based on the chapter titles. Still, the simple fact that I may wish to reread sections or relate them to others attests to the strength of this book.

As previously stated, this is not a history text in which to look up simple events and dates; rather, it is a rich personal story of one individual's professional and personal life experiences. Dr. Zeitlin relates in his preface that "what we still do is so frightening that I reflect this in the title of the book - Laughing and Crying about Anesthesia." In his memoir, Dr. Zeitlin successfully traces the progression of the reduction of risk and the improvement of safety in anesthesia in an enjoyable read for both nonmedical readers and anesthesiologists alike. Furthermore, he presents a rare glimpse into the day-to-day world of precisely what we, as anesthesiologists, do along with some of the stresses we face. And yes, I did both laugh and cry...

Competing interests None declared. 